\title{
Postcapillary Venule
}

National Cancer Institute

\section{Source}

National Cancer Institute. Postcapillary Venule. NCI Thesaurus. Code C33345.

The first potion of the venous component of the microcirculation composed of

endothelial cells, pericytes, and a basement membrane, which is one of the main sites for the interchange of gas and metabolite molecules between the tissues and the blood. 